\title{
REVIEW ON HERBAL LOZENGES PREPARED FOR COLD AND FLU.
}

\author{
Mudgal Kajal ${ }^{1}$, Dr. Koko Sweta.S ${ }^{2}$, Dr. Darwhekar G. $\mathbf{N}^{3}$
}

1,2,3 Acropolis Institute of Pharmaceutical Education and Research

Article Info: Received 17 April 2021; Accepted 11 June 2021

DOI: https://doi.org/10.32553/jbpr.v10i3.869

Corresponding author: Mudgal Kajal

Conflict of interest statement: No conflict of interest

\begin{abstract}
Traditional medicine and herbal formulation have been used by mankind for the care and treatment of various diseases and disorder. Throat infections are most common diseases in today's world. However it is not taken too seriously by people long term throat infection can lead to severe throat problems pharyngitis and also cancer. The polyherbal lozenges are solid preparation that contains one or more medicaments usually during a flavored, sweetened base that are intended to dissolve or disintegrate slowly within the mouth. The benefits of they medicated lozenges is that they increase a retention time of the dosage form in mouth which increases bioavailability, reduces gastric irritation and bypasses first pass metabolism.
\end{abstract}

Keywords: polyherbal lozenges, pharyngitis

\section{Introduction}

\section{HERBAL DRUGS:}

In recent time there's a rise in global utilization of herbal medicine within the treatment of varied diseases affecting human. The highly safety profile and low-cost herbal medicines are reported because the major factors liable for the increased upsurge in herbal medication. The subject of the phytochemical analysis, photochemistry or plant chemistry has developed in recent years as a definite discipline, somewhere in between natural product chemistry and plant biochemistry and it is closely related to both. It is concerned with the extensive variety of organic substances that are complex and accumulated by plant and deals with the chemical structures of this substance, their biosynthesis, metabolism, their natural distribution and biological function.(1)

Herbal medicine remains the mainstay of about 75-80 percentage of the earth population, mainly within the developing countries, for primary health care thanks to better culture acceptability, better compatibility with the human body and lesser side effects. However, the previous couple of years have seen a serious increase within their use in the developed world. Medicinal plants contain additional active principles apart from the most active principles and physiological inert substances like cellulose and starch. Unlike the chemical entities, which contains one active ingredient pulps a number of inert substances, which makeup the dosage form (like tablet, capsules and syrups). (2)

Indian system of medicines consists of Ayurveda, Unani, siddha, Homeopathy, Naturopathy, and Yoga. Each of which uses the herbal constituents in some or the other form, crude drug is not so effective because they have not have been tested for efficacy according to rigid pharmacological standards. As the constituents derived from the medicinal plants proved to cure the human disorders they 
isolated and used for their pharmacological action. (3)

A WHO survey has reported that about 70-80 percentage of world s population rely chiefly on traditional medicines, mainly on herbal resources, in their primary healthcare. Towards the end of twentieth century herbal medicine become more main stream throughout the world, partly as a result of the value of traditional medicine systems, particularly an Asian origin. We have also seen an increase in the popularity and use of natural remedies in developed countries, including herbs, herbal medicines, over the counter health food, nutraceuticals, and herbal medicines products. Overall, the world market for herbal medicines and product is increasing rapidly, especially for
Chinese, German, and Indian herbal medicine. (4)

\section{BENEFITS OF HERBAL DRUGS:}

- Herbal drugs have long era of use and better patient tolerance and public acceptance.

- Herbal drugs act as a reversible source, which is our only hope for sustained supplies of cheaper medicines for the growing population.

- The cultivation and processing of medicines herbs and herbal product is environment friendly.

- Throughout the world, herbal medicines have provided many of the most useful and vast variety to the medicinal science.(5)

Table 1: HERBAL INGREDIENT:

\begin{tabular}{|c|c|c|c|c|c|}
\hline S.NO & $\begin{array}{l}\text { COMMON } \\
\text { NAME }\end{array}$ & SCIENTIFIC NAME & FAMILY & $\begin{array}{l}\text { CHEMICAL } \\
\text { CONSTITUENTS }\end{array}$ & USES \\
\hline 1. & $\begin{array}{l}\text { Rosary pea, } \\
\text { Jeqiuirity Bean }\end{array}$ & Abrus precatorius & Fabales & $\begin{array}{l}\text { Abrin, acid } \\
\text {,Cycloartenol, Luteolin, } \\
\text { Isoorientin }\end{array}$ & $\begin{array}{l}\text { Bark decocation is } \\
\text { employed is cough.Bark } \\
\text { paste is additionally } \\
\text { externally is wounds and } \\
\text { skin diseases.Fruits are } \\
\text { eaten in diarrhea and } \\
\text { dysentery. }\end{array}$ \\
\hline 2. & Brahmi & Bacopa Monnieri & Plantaginaceae & $\begin{array}{l}\text { Alkaloid, Nicotinine, } \\
\text { Herpestin, Bacosides A } \\
\text { and B C, Triterpenoid } \\
\text { saponins, Stigmastanil, }\end{array}$ & $\begin{array}{l}\text { Leaf extract is given to } \\
\text { extend memories and } \\
\text { also used for relieving } \\
\text { cough. }\end{array}$ \\
\hline 3. & Hingot, Desert date & Balanites aegyptiace & Zygophyllaceae & $\begin{array}{l}\text { Protein and Lipid and } \\
\text { Carbohydrate and many } \\
\text { more Alkaloid, Saponin } \\
\text {, Flavonoid, and } \\
\text { Organic acid. }\end{array}$ & $\begin{array}{l}\text { The fruit can cure mouth } \\
\text { ulcer, pertussis, sleepy } \\
\text { sickness and skin } \\
\text { diseases. }\end{array}$ \\
\hline 4. & $\begin{array}{l}\text { Air potato, air yam } \\
\text {, aerial yam and } \\
\text { parsnip yam }\end{array}$ & Dioscorea bulbifera L & Dioscoreaceae & $\begin{array}{l}\text { Fourteen compounds } \\
\text { are isolated and } \\
\text { identified as } \\
\text { stigmasterol and } \\
\text { Monoarachidin. }\end{array}$ & $\begin{array}{l}\text { Root paste mixed with } \\
\text { cow milk is given orally } \\
\text { for the treatment of } \\
\text { cough and asthma. }\end{array}$ \\
\hline 5. & Morning glory & Evolvulus alsinoides & Convolvulaceae & $\begin{array}{l}\text { Chemical compounds } \\
\text { isolated from E. } \\
\text { alsinoides include } \\
\text { scopoletin and } \\
\text { umbelliferone and } \\
\text { scopolin and one more } \\
\text { 2- methyl -1,2,3,4,- } \\
\text { butanetetrol. }\end{array}$ & $\begin{array}{l}\text { Leaf extract is given } \\
\text { orally in they teretment } \\
\text { of cough and cold. }\end{array}$ \\
\hline 6 & Gurmar & Gymnema sylvestre & Apocynaceae & $\begin{array}{l}\text { Gymnema include } \\
\text { gymnemic acid,tartaric } \\
\text { acid, calcium oxalate, } \\
\text { glucose. }\end{array}$ & $\begin{array}{l}\text { Leaf juice is taken orally } \\
\text { in diabetes and } \\
\text { asthma.(6) }\end{array}$ \\
\hline 7 & Mulhatti & Glycryrrhiza glabra linn & Leguminnosae & $\begin{array}{l}\text { Isoliquiritegenin, } \\
\text { glabrena, Liquiritin, } \\
\text { glycyrrhiza }\end{array}$ & $\begin{array}{l}\text { Anti malariyal activity, } \\
\text { Anti hyperglycemic } \\
\text { activity,anticoagulant.(7) }\end{array}$ \\
\hline
\end{tabular}




\begin{tabular}{|l|l|l|l|l|l|}
\hline 8. & Harad & Terminalia chebula & Combretaceae. & $\begin{array}{l}\text {. Shikimic acid and } \\
\text { Ferulic acid and } \\
\text { Vanillic acid and P } \\
\text { Coumaric acid. }\end{array}$ & $\begin{array}{l}\text { Anti inflammatory } \\
\text { activity.(8) }\end{array}$ \\
\hline 9. & Ginger & Zingiber officinale & Zingiberaceae & $\begin{array}{l}\text { Gingerol, Shogaol, } \\
\text { Paradol,Zingiberene. }\end{array}$ & $\begin{array}{l}\text { Treatment of pain, } \\
\text { hypoglycemic } \\
\text { potentials.(9) }\end{array}$ \\
\hline 10. & Kuth & Sussura lappa & & $\begin{array}{l}\text { Alkaloids, flavanoids, } \\
\text { tannins, steroids . }\end{array}$ & $\begin{array}{l}\text { Lower down fever } \\
\text { related to cold and flu. }\end{array}$ \\
\hline & & & & & \\
\hline
\end{tabular}

\section{Cold and Flu:}

Cold and influenza are both respiratory ailments and the terms are utilized reciprocally. In any case they are both brought about by various infections. There are two fundamental kinds of seasonal infections flu A and flu B. The most genuine and dangerous influenza flare-ups are brought about by flu A due to its capacity to hereditarily move into new structures against which no individual has created invulnerability. Flu B for the most part causes less extreme contamination. Flare-ups of flu B usually happen in schools and military camps where numerous individuals live or work in very close contact. This season's virus is a more genuine disease than basic virus. With chilly the side effects are based spot on and throat. In any case seasonal influenza influences the entire body.(11)

\section{LOZENGES:}

Lozenges are solid preparations that contain one or more medicaments, usually during a flavored and sweetened base, that are intended to dissolve or disintegrate gently within the mouth. They can be making by molding (gelatin and/or fused sucrose or sorbitol base) or by compression of sweetened based tablets. Molded lozenges are sometimes mentioned as pastilles, whereas compressed lozenges could also be mentioned as troches. They are used for patients who cannot consume solid oral dosage forms well as for they medications designed to be released slowly to yield a continuing level of drug in a oral cavity to the throat tissues in a solution of the drug. Lozenges historically are used for the succour of minor pharyngitis pain and irritation in they thort and are used extensively to deliver topical anesthetics and antibacterial. Today they're used for of medicine like analgesics, anesthetics, antimicrobials, antiseptics and antitussives or aromatics any other types of medicine astringents, corticosteroids, decongestants, and demulcents and other classes and combinations. They are easy to handle, the dose has been apportioned, and thus the excipients have a demulcent effect on throat since the ingredients are released slowly and spread uniformly over the affected mucosal membrane.

\section{Advantages}

It is easy to administer to both pediatric or geriatric patients. It has a satisfying taste and may extend the time a quantity of drug remains within the mouth to elicit local activity. Systamic absorption of medicine are often possible through cavity. It can be prepared with minimal equipment. Taste of the drugs are often masked by sweetners and flavours utilized in the formulation.

\section{Disadvantages}

It might be mistakenly used as candy by children. Parents should be cautioned to not associate medications with candy and to stay the merchandise out of the reach of youngsters . Some drugs might not to be suitable with aldehyde candy bases eg; benzocaine. Heat stable drugs are suitable. Children having above 6 years aged can use lozenges safely. Drugs having minimum bitter taste are suitable.(12)

\section{METHOD OF PREPARATIONS}

For compressed tablet lozenges:-

There are 2 types they are;

a. Direct compression b. Wet granulation

a. Direct compression: candy lozenges are mixtures of sugar and other carbohydrates in an 
amorphous(noncrystalline) or glossy state. They can even be considered solid syrups of sugars. In the direct compression the all ingredients are often thoroughly mixed and directly compressed to make a lozenge.

\section{b. Wet granulation:}

- In this sugar is pulverized by mechanical combination to a fine powder $(40-80$ mesh $)$.

- Medicament is added and mass is blended.

- The blended mass is subjected to they granulation with sugar or syrup and screened

- Through $2-8$ mesh size . This is considered by drying and milling to $10-30$ mesh size .

- Flavour and lubricant are added prior to compression.(13)

\section{Types of Lozenges}

\section{According to Site of Action}

1. Local effect. Ex. Antiseptic, Decongestants

2. Systemic effect. Ex. Vitamins, Nicotine

\section{According to texture and Composition}

1. Chewy or caramel based medicated lozenges

2. Compressed tablet lozenges

3. Soft lozenges

4. Hard candy lozenges (14)

\section{According to Site of Action}

Lozenges are classified into various classes supported various methods like consistent with the location of action which may either be local or systemic effect. Examples of local effect are antiseptic or decongestion, while vitamins and nicotine and many more example of systemic effect.(14)

\section{According to Texture and Composition}

\section{Chewy or Caramel Based Medicated Lozenges}

These are they dosage form during which medicament is incorporated into a caramel base which is chewed rather than being dissolved in mouth. These lozenges are effective used for they pediatric patients and It's a very effective means of administering medications for gastrointestinal absorption and systemic use.
One of the more popular lozenges for pediatric use is that the chewable lozenge, or "gummytype" of candy lozenge. These gelatin based pastilles were produced by pouring the melt into molds or out into a sheet of uniformty thickness. (14)

\section{Manufacturing of chewy or caramel based medicated lozenges}

The candy base lozenges is cooked at 95 to $125^{\circ} \mathrm{C}$ and transferred to planetary or sigma blade mixer. Mass is allowed to cool to $120^{\circ} \mathrm{C}$. This is can be considered by the addition of whipping agent below $105^{\circ} \mathrm{C}$. The medicaments are then added between 95$105^{\circ} \mathrm{C}$. Color is a dispersed in humectants and added to the above mass at they temperature above $90^{\circ} \mathrm{C}$. Seeding crystals and flavors are then added below $85^{\circ} \mathrm{C}$. Followed by they lubricant addition above $80^{\circ} \mathrm{C}$. Candies are then formed by rope forming. (14)

\section{Compressed Tablet Lozenges}

When the active ingredient is heat sensitive, it's going to be prepared by compression. The granulation method is analogous thereto used for any compressed tablet. These tablets differ from conventional tablets in terms of organoleptic property, Non disintegrating characteristics and slower dissolution profiles. The lozenge is formed using heavy compression equipment to offer a tablet that's harder than usual, because it is desirable for the troche to dissolve slowly in mouth. Commercially, the preparation of lozenges by tablet compression is a smaller amount important.(14)

\section{Manufacturing of Compressed tablet Lozenges}

Manufacturing process of compressed tablet lozenges can either be direct compression and wet granulation. In direct compression, ingredients are thoroughly mixed then compressed. In wet granulation, sugar content is pulverized by mechanical combination to a fine powder (40-80 mesh size). Medicament is added and thoroughly blended. The blended mass is subjected to granulation with sugar or syrup and screened through 2-8 mesh screens. 
this is often followed by drying and milling to 10-30 mesh size. Flavor and lubricant are then added before compression.(14)

\section{Soft Lozenges}

Soft lozenges became popular due to the convenience of extemporaneous preparation and applicability to a good sort of drugs. The bases usually contains a mix of varied polyethylene glycols, acacia or similar materials. One sort of these soft lozenges is that the pastille, which is defined as a soft sort of lozenge, usually transparent, consisting of a medicine during a gelatin, glycerol-gelatin or acacia: sucrose base. they're easy to use, convenient to hold, easy to store (room temperature), and are generally pleasant tasting. Polyethylene glycol-based lozenges may have a bent to be hygroscopic and should soften if exposed to high temperatures.(14)

\section{Manufacturing of soft lozenges}

On the account of the soft texture of those lozenges, they will be hand rolled then dig pieces or the nice and cozy mass are often poured into a plastic mold. Mold cavity should be overfilled if PEG is employed, as PEG's contract as they cool. this is often not required just in case of chocolate because it doesn't shrink.(14)

\section{Hard Candy Lozenges}

Hard candy lozenges are mixtures of sugar and other carbohydrates in an amorphous (noncrystalline) or glassy state. They can even be considered solid syrups of sugars. The moisture content and weight of candy lozenge should be between, 0.5 to $1.5 \%$ and $1.5-4.5 \mathrm{~g}$ respectively. These should undergo a slow and uniform dissolution or erosion over 5- 10min., and should not disintegrate. The temperature requirements for his or her preparation is typically high hence heat labile materials can't be incorporated in them. These pastilles were prepared by Heating and congealing method. (14)

\section{Manufacturing of hard Candy Lozenges}

The candy base is cooked by dissolving desired quantity of sugar in one third amount of water during a candy base cooker. This is continued till the temperature rises at to $110^{\circ} \mathrm{C}$. Corn syrup is added and cooked till the temperature reaches 145 to $156^{\circ} \mathrm{C}$. The candy mass is faraway from the cooker and transferred to a lubricated transfer container mounted onto a weight check scale where the load of the mass is checked. This is followed by color addition in form of solutions and pastes or color cubes. The mass is then transferred to a water-jacketed chrome steel cooling table for mixing and therefore the flavor, drug and ground salvage is added. The mass is either poured in mold or pulled into a ribbon while cooling then move desired length. The obtained lozenges are packaged.(14)

\section{Formulation and Evaluation of Lozenges}

Diameter and thickness- Diameter of the lollipop is significant for uniformity of lozenges size. It are often measured using Vernier Calipers. The extent to which the diameter of the lozenges deviated from $\pm 5 \%$ of the quality value.

Hardness- The protection of lozenges to shipping or breakage under they conditions of storage, transportation and handling before usage depends on its hardness. The hardness of lollipops are often measured by using Monsanto hardness tester. The hardness was measured in terms of $\mathrm{kg} / \mathrm{cm} 2$.

Weight Variation- The USP weight variation test is completed by weighing 20 lozenges individually, calculating the typical weight and comparing the individual weights to the typical . Formula of Weight Variation = Average weight - Initial weight Average weight.

\section{Drug excipients interaction studies- Determined by FTIR.}

Friability - Determined by Roche Friabilator operated at They $25 \mathrm{rpm}$ for $4 \mathrm{~min}$.

In-vitro drug release- this is often often administered in USP II paddle type dissolution apparatus.

Drug content- convenient number of lollipop are crushed and dissolved in an appropriate 
solvent and thus the absorbance of the solution is measured spectrophotometrically.(14)

\section{Applications of lozenges}

Antifungal lozenges: Oral lozenges, such as clotrimazole and nystatin, are used to treat fungal infections.

Nicotine lozenges: Nicotine lozenges are mostly used as a method to quit smoking. The lozenges release nicotine into bloodstream when $\mathrm{u}$ suck on the lozenges, consistent with the Mayo clinic. Nicotine smokings are intended to be useful as often as necessary, until the craving to smoke ceases.

Zinc lozenges: Zinc is used as an antioxidant to help your body fight against they infections. When contained in lozenges, zinc is assumed to assist reduce the duration of colds and symptoms. Yet, the Mayo clinic notes that there are conflicting studies on whether those zinc claims are accurate.

Throat/cough lozenges: sore throat lozenges contain an anesthetic, such as benzocaine, to soothe your throat. The anesthetic works by numbing the affected area to provide temporary reliefer. Some throat lozenges also might contain an antibiotic to treat diseases of the throat infection and including strep throat. Cough lozenges which suppress coughing, can contain ingredients, like menthol or eucalyptus.

Erectile dysfunction lozenges: According to the New Zealand men's clinic, lozenges are available to treat erectile dysfunction. The lozenges are administered up to the 30 minutes before intercourse erectile dysfunction lozenges have less side effects than tablet forms.

Morning sickness lozenges: Prenatal lozenges contain pyridoxine, or vitamin B6 helps to relieve nausea and vomiting symptoms. The use of prenatal lozenges should be taken as directed by your physician, since high doses of B6 during pregnancy can cause side effects in your newborn.(14)

\section{Conclusion}

Lozenges are they medicated confections that are develop about 20 th century ago and are still under commercial production. Lozenges are organoleptically accepted formulation by the pediatric patients and patients having dysphasia. They are the foremost natural and easiest route of drug administration. They are easy to prepare and store. Lozenges are adopted for both local and systemic administration and a good range of active ingredients are often incorporated in them. Sweetened and flavored lozenges are today's demands. They are expected to acquire more demand in pharmaceutical production as innovative dosage form for the potent drugs which seem to be an ideal dosage form. Most of the preparations are available over the counter products andvery economic dosage form. Lozenges enjoy a crucial position in pharmacy and can still remain so in future

\section{References}

1. Kritikar, K. R., and Basu B. D. (1935) Indian medicinal plants, Periodical Experts, Vol (1) 1347-1348.

2. Nadkarni, A. K. (1989) Indian Material Medica Popular book depot, Bombay, India Vol (1) 1186.

3. Rastogi, R., and Mehrotra B. (1991) Compendium of Indian medicinal plants new delhi vol (2) 1234.

4. Agarwal, S. S. and Prabhadevi, M. (2007) Herbal drug Technology first Edition: Universities press 2-3.

5. Author Handbook of pharmaceutical excipients (2009), pharmaceutical press.

6. Ray M., Sheikh M and Mishra M. (2011) Ethnomedicinal plants used by tribals of east nimar region, Madhya Pradesh, vol. 10(2) 367-371.

7. Damle, M. (2014) 'A Review on Glycyrrhiza glabra (Liquorice) - a potent medicinal herb', International Journal of Herbal Medicine, 2(2),132-136.

8. Promila., and Madan Vk. (2018) Therapeutic \& Phytochemical Profiling of Terminalia chebula Retz. (Harad): A Review, Journal of Medicinal Plants Studies; 6(2): 25-31.

9. Prasad, S., and Tyagi, K. A. (2015) 'Ginger and Its Constituents: Role in 
Prevention and Treatment of Gastrointestinal Cancer', Hindawi Publishing Corporation Gastroenterology Research and Practice Volume, (11) 1-11.

10. Ansari S. (2019) Ethnobotany and Pharmacognosy of Qust/ Kut (Saussurea lappa, C. B. Clarke) with Special Reference of Unani Medicine, Pharmacogn Rev. 2019;13(26):71-76.

11. Kalra, M., Khatak, M., and Khatak, S. (2011) 'Cold and flu conventional and botanical and nutritional therapy', International Journal of Drug Development \& Research, 3(1), 314- 327.
12. Pothu, R., and Rao, Y. M. (2014) 'Lozenges Formulation and Evaluation: A Review', International Journal of Advances in Pharmaceutical Research, 5(5), 290-298.

13. Pokale, D., Apurva, T. K. Shrikant, and Bodhankar, M. (2019) Medicated Chewable Lozenges: A Review', International Journal of Recent Scientific Research, 10(1),32071-32076.

14. Rathod, M., Poharkar, S., Pandhre, Y., Monali, M., and Sandesh, S. (2018) Medicated Lozenges As An Easy To Use Dosage Form', World Journal of Pharmaceutical Research, 7(16),305-322. 